\title{
Grey Clustering Evaluation Model Based on D-S Evidence Theory to Evaluate the Scheme of Basin Initial Water Rights Allocation
}

\author{
L.N. Zhang ${ }^{1, *}$, F. P. Wu ${ }^{1}$, L.L.Yu ${ }^{2}$ and X. Wang ${ }^{1}$ \\ ${ }^{1}$ Business School of Hohai University, Nanjing, 210098, PR China \\ ${ }^{2}$ School of Business JIT, 211169, PR China
}

\begin{abstract}
In view of the characteristics of the randomness and uncertainty of basin initial water rights allocation scheme evaluation, this paper, integrating the Dempster-Shafer (D-S) evidence theory and the grey clustering evaluation method, researches on the evaluation method of allocation scheme. Taking advantages of D-S evidence theory and the compactcenter-point triangular whitenization weight function (CCTWF) in processing and integrating the uncomplete information, the grey clustering evaluation model based on D-S evidence theory is proposed. The integrated clustering coefficients matrix is obtained by using the grey clustering evaluation method based on CCTWF, and we look each clustering object as an evidence. Then, D-S evidence theory is used to obtain the belief function of every evidence with application of Dempster's combination rule, and the result of scheme evaluation in terms of the principle of selecting maximum value of belief functions. Finally, we take the evaluation of basin initial water rights allocation scheme of Dalinghe River in China for instance to demonstrate the practicability and effectiveness of this model.
\end{abstract}

Keywords: D-S evidence theory, evaluation model, grey clustering evaluation, grey system theory, initial water rights allocation.

\section{INTRODUCTION}

Owing to the impact of human activities and climate change, the increasing water demands, unreliable water supplies and deteriorated water systems make the condition of the shortage of water resourses exacerbated gradually $[1,2]$. Now water shortage has been considered as a major obstacle to sustainable development of water resources, specially in society and economy $[3,4]$. In China, this problem of water shortage, which may be resulted by the explosion of urban population, uneven distribution of water resources in time and space, water contamination or low efficiency of water utilization etc, becomes more serious and restricts the social and economic development of some areas in this country [5]. In order to resolve the serious shortage of water resources in China, Chinese government put forward "the strictest water resources management system" in 2010, and set up "the three red lines" to assure this system implemented. "The three red lines" includes: the red line of water resources development, the red line of controlling water-use efficiency and the red line of controlling wastewater emission of water functional area [6]. The theory and practice of basin initial water rights allocation must adapt to the requirements of this system.

The allocation of basin initial water rights is a process to achieve a equitable allocation of the basin initial water rights among basin natural water rights, initial water rights of provinces and government reserved water of basin according to certain rules [7]. And It's also an important approach to

*Address correspondence to this author at the Business School of Hohai University, Nanjing, 210098, P.R. China; Tel: 025-58099312;

Fax: 025-86902496; E-mail: linazhangv@163.com bring about fair, reasonable and effective water resources allocation among various regions and businesses [8]. To take account of the current situation of water scarcity, establishing water rights institution on the basis of initial water rights allocation can improve water allocation efficiency among various water using sectors or regions, because it will stimulate water users to establish internal incentive and constraint mechanism of energy saving and emission reduction $[9,10]$. The allocation of basin initial water rights to determine annual water use caps for different users in a reasonable and transparent way underpins better water resources management [11]. "Coase Theorem" states that the basin initial water rights allocation is conductive to define property rights and reduce transaction costs [12].

In recent decades, along with the implement of "the strictest water resources management system", much attentions have been focused on water rights allocation system for optimizing allocation of water resources in China [5, 13-15]. The performance of the basin initial water rights allocation scheme directly affects the efficiency of water resources utilization. Hence, for the constraints of "the strictest water resources management system", establishing scientific and systematic evaluation index system and effective evaluation method of allocation scheme is critical to guide water resources management. An initial allocation of water rights is often complicated with a number of economic, social, environment, political and technical facters, coupled with vaurious uncertainties and randomness [2]. So it need to construct a logical evaluation method with multiple perspectives.

As a result, a large number of efforts were undertaken in developing evaluation method for solving (to reflect these) uncertainty and random problems. According to the actual 
situation of basin in the world, many researchers and scholars have contributed methods of the basin initial water rights allocation scheme evaluation. The commonly used evaluation methods mainly include Lattice-Order Theory [13], Fuzzy Mathmatics [16], Analytic Hierarchy Process(AHP) [17], Data Envelopment Analysis(DEA) [18], and Grey Clustering Evaluation [19-22]. Although these methods or models have been used widely and successfully in dealing with uncertainty and random problems, there are some limitations when they are applied in basin initial water rights allocation scheme evaluation. Lattice-Order Theory is effective to select the optimal deployment from several schemes, but usually inappropriate to evaluate a scheme. Fuzzy Mathmatics and AHP are over-dependent on expert'decisions, and ignore the trait and uncertainty information contained in the data, which makes the result a little subjective to some extent. Owing to the problems of statistics data quality and measurement error, abnormal data may occur during the process of evaluation. The stability of the results by DEA is very sensitive to outliers. Grey clustering evaluation is part of the grey system theory, which is suitable for evaluating objects only with partial and uncertainty information. Whitenization weight function is the key technology to grey clustering evaluation and directly affects the evaluation reliability [14]. Whitenization weight function refers to the preference for different values of a grey variable within its scope.

To address the construction of whitenization weight function, a number of optimization techniques were developed, and is widely used in the fields of evaluation research, such as resources allocation, traffic safety and the construction of road system, the information system functional requirements, web sites [14, 19, 21-27]. Liu and Zhu developed whitenization weight function and proposed the grey clustering evaluation method based on the end-point triangular whitenization weight function (ETWF) to evaluate the construction of universities [19]. Besides, Liu and Xie did further research on the theory of ETWF, proposed the grey clustering evaluation method based on the center-point triangular whitenization weight function(CTWF), and proved that CTWF precedes ETWF in several aspects, such as the crossing properties of a grey cluster, rules for choosing end-points and clustering coefficients [23]. Motivated by the ideas of grey clustering evaluation based on ETWF and CTWF, Zhang et al. proposed grey clustering evaluation based on the compact-center-point triangular whitenization weight function (CCTWF) by taking the problem of which the division of grey clustering interval of triangular whitenization weight function is lack of certain scientific ideals as the breakthrough point, and applied it in the evaluation of basin initial water rights allocation scheme [14].

However, according to the principle of the maximum clustering coefficient value, grey clustering evaluation based on CCTWF can merely determine the grey clustering result, which makes the uncertainty information of the clustering objects obtained from the grey clusters hardly appropriate. At present, some researchers and scholars have integrated grey clustering evaluation and D-S evidence theory, to study post-evaluation for the public investment projects, wherein grey clustering evaluation based on whitenization weight function is applied to determine the grey clustering coeffi- cient value, and D-S evidence theory is used to obtain the belief function of each evidence with application of Dempster's combination rule [28-32].

Motivated by the ideas of integrating grey clustering evaluation and D-S evidence theory, based on the previous researches, this paper, taking advantages of CCTWF and D$\mathrm{S}$ evidence theory in processing and integrating the uncomplete information, proposes a grey clustering evaluation model based on D-S evidence theory. The integrated clustering coefficients matrix is obtained by using the grey clustering evaluation method based on CCTWF, and we look each clustering object as an evidence. Then, the D-S evidence theory is used to obtain the belief function of each evidence with application of Dempster's combination rule, and the result of scheme evaluation is reached from the principle of the maximum belief functions value.

The remainder of this paper is organized as follows: the next section briefly introduces the procedure of constructing the grey clustering evaluation model based on D-S evidence theory, which can be summarized as obtaining the grey clustering result of each criteria by the grey clustering evaluation method based on CCTWF and combinatting the comprehensive evaluation result of allocation scheme based on D-S evidence theory. In Section 3, the new method is applied to evaluate the basin initial water rights allocation scheme of Dalinghe River to demonstrate its feasibility and practicability. The final section concludes by discussing our findings.

\section{MODELING FORMULATION}

The procedure of grey clustering evaluation model based on D-S evidence theory can be summarized as follows: (1) By calculating the integrated clustering coefficients matrix by the grey clustering evaluation method based on CCTWF, then we get the grey clustering result of each criteria in terms of the principle of selecting the maximum value of clustering coefficients. (2) By combinatting the belief function of each evidence with application of Dempster's combination rule, we get the result of allocation scheme evaluation in terms of the principle of selecting the maximum value of belief functions. Fig. (1) shows a flowchart for constructing the grey clustering evaluation model based on D-S evidence theory.

\subsection{Obtain the Grey Clustering Result of Each Criteria}

We can calculate the integrated clustering coefficients matrix by the grey clustering evaluation method based on CCTWF. The procedure for calculating the integrated clustering coefficients matrix can be generated as follows:

For describe it properly, we make the following assumptions:

$\mathrm{S}=\{$ The comprehensive evaluation of an initial water rights allocation scheme $\}$ : evaluation (clustering) object set;

$O=\left\{O_{1}, O_{2}, O_{3}, O_{4}\right\}=\{$ Society, Economic, Ecology, Efficiency $\}$ : evaluation sub-object(criteria) set;

$k, k \in\{1,2,3,4\}$ : evaluation grey categories, corresponding to poor type, general type, good type and excellent type respectively; 


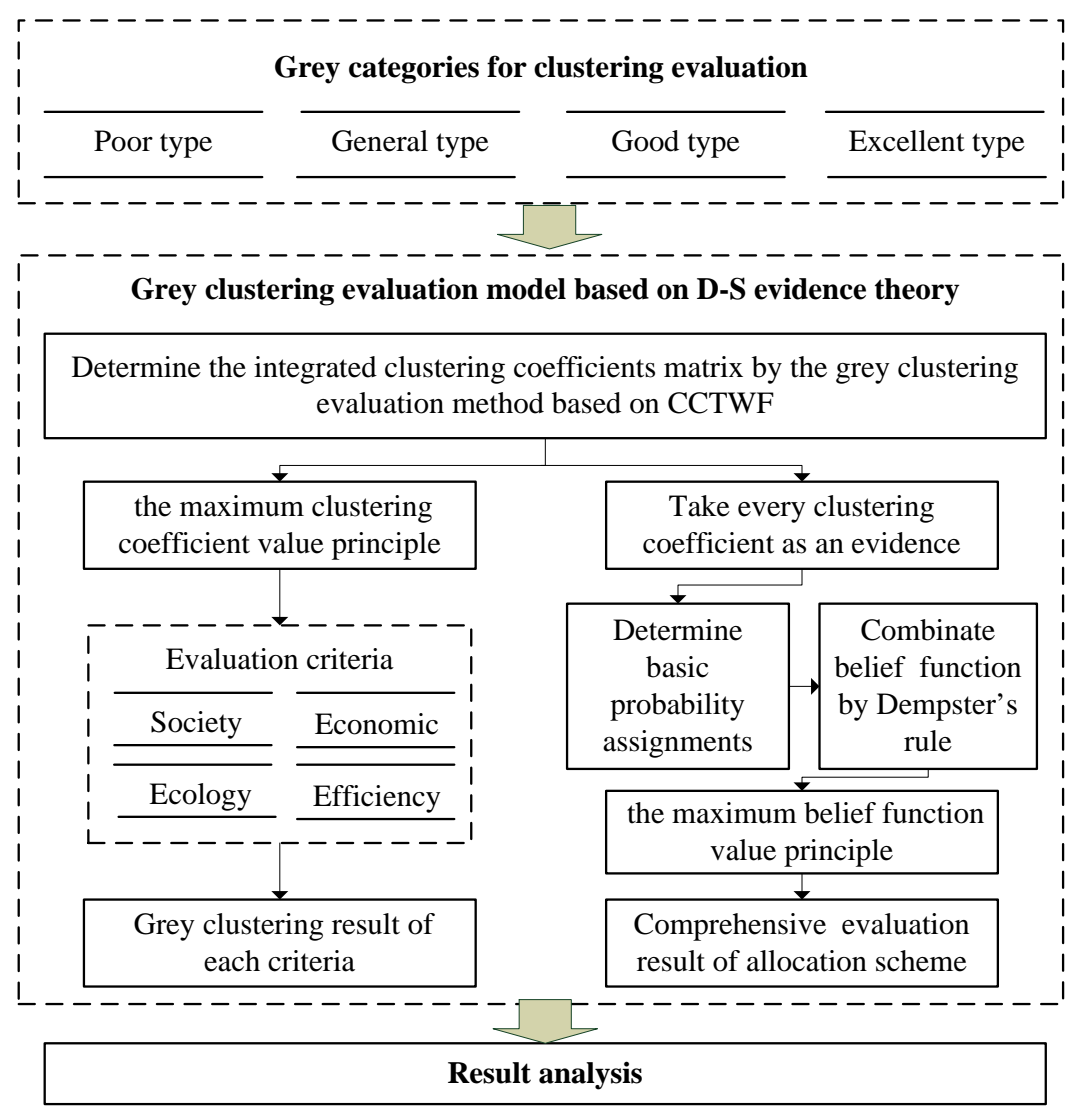

Fig. (1). Flowchart for constructing the grey clustering evaluation model based on D-S evidence theory.

$g=\left\{g_{j}^{i} \mid i=1,2,3,4 ; j=1,2, \ldots, m\right\}:$ evaluation index set, where $g_{j}^{i}$ is the index $j$ for sub-object $O_{i}$;

$x_{j}^{i}, i=1,2,3,4 ; j=1,2, \cdots, m:$ observation value of the clustering index.

Step 1: Assuming $\lambda_{j}^{1}, \lambda_{j}^{2}, \cdots, \lambda_{j}^{s}$ are the grey center points of the evaluation index $g_{j}^{i}$ for subject $O_{i}$, and the range of value allowed for $x_{j}^{i}$ is $\left[a_{j}^{1}, a_{j}^{k+1}\right]$, then we can get center points $\lambda_{j}^{0}, \lambda_{j}^{k+1}$ by extending grey cluster in left-right direction.

Step 2: Let $b_{j}^{k+1}=\frac{\lambda_{j}^{k}+\lambda_{j}^{k+1}}{2}, k=1,2,3,4$, we have two scenarios for determining grey interval.

(1) If $\lambda_{j}^{k}=\frac{b_{j}^{k}+b_{j}^{k+1}}{2}$, then the grey interval of the grey cluster $k$ is given by $\left[b_{j}^{k}, b_{j}^{k+1}\right)$;

(2) If $\lambda_{j}^{k} \neq \frac{b_{j}^{k}+b_{j}^{k+1}}{2}$, take $\Delta_{k}=\max \left\{\lambda_{j}^{k}-b_{j}^{k}, b_{j}^{k+1}-\lambda_{j}^{k}\right\}$, then the grey interval of grey cluster $k$ is given by $\left[c_{j}^{k}, c_{j}^{k+1}\right)=\left[\lambda_{j}^{k}-\Delta_{k}, \lambda_{j}^{k}+\Delta_{k}\right)$, thus, we can get $c_{j}^{1}=\min \left\{a_{j}^{1}, b_{j}^{1}, c_{j}^{1}\right\}$ and $c_{j}^{k+1}=\max \left\{a_{j}^{k+1}, b_{j}^{k+1}, c_{j}^{k+1}\right\}$.
Let $\left[c_{j}^{k}, c_{j}^{k+1}\right)$ be the grey interval of grey cluster $k$, connecting points $\left(c_{j}^{k}, 0\right),\left(\lambda_{j}^{k}, 1\right)$ and $\left(c_{j}^{k+1}, 0\right)$, then the triangular whitenization weight function of the evaluation index $g_{j}^{i}$ belonging to grey cluster $k$ is defined $f_{j}^{k}(\cdot), j=1,2, \cdots$ ,$m ; k=1,2,3,4$.

we can calculate $f_{j}^{k}(\cdot), j=1,2, \cdots, m, k=1,2,3,4$ for any observation value $x_{j}^{i}$ of the evaluation index $g_{j}^{i}$ :

$$
f_{j}^{k}\left(x_{j}^{i}\right)= \begin{cases}0, & x_{j} \notin\left[c_{j}^{k}, c_{j}^{k+1}\right) \\ \frac{x_{j}^{i}-c_{j}^{k}}{\lambda_{j}^{k}-c_{j}^{k}}, & x_{j} \in\left[c_{j}^{k}, \lambda_{j}^{k}\right) \\ \frac{c_{j}^{k+1}-x_{j}^{i}}{c_{j}^{k+1}-\lambda_{j}^{k}}, & x_{j} \in\left[\lambda_{j}^{k}, c_{j}^{k+1}\right)\end{cases}
$$

The same procedure may be easily adapted to calculate the triangular whitenization weight function $f_{j}^{k}(\cdot)$ of the evaluation index $g_{j}^{i}$ for any $x_{j}^{i} \in\left[b_{j}^{k}, b_{j}^{k+1}\right)$.

$$
\text { If }\left[c_{j}^{k-1}, c_{j}^{k}\right) \cap\left[b_{j}^{k}, b_{j}^{k+1}\right) \neq \varnothing \text {, there exists } j_{o} \in\{1,2, \cdots, m\}
$$
such that $x_{j_{0}}^{i} \in\left[c_{j}^{k-1}, c_{j}^{k}\right) \cap\left[b_{j}^{k}, b_{j}^{k+1}\right)$, we take $f_{j_{0}}^{k^{\prime}}\left(x_{j_{0}}^{i}\right)=$ 


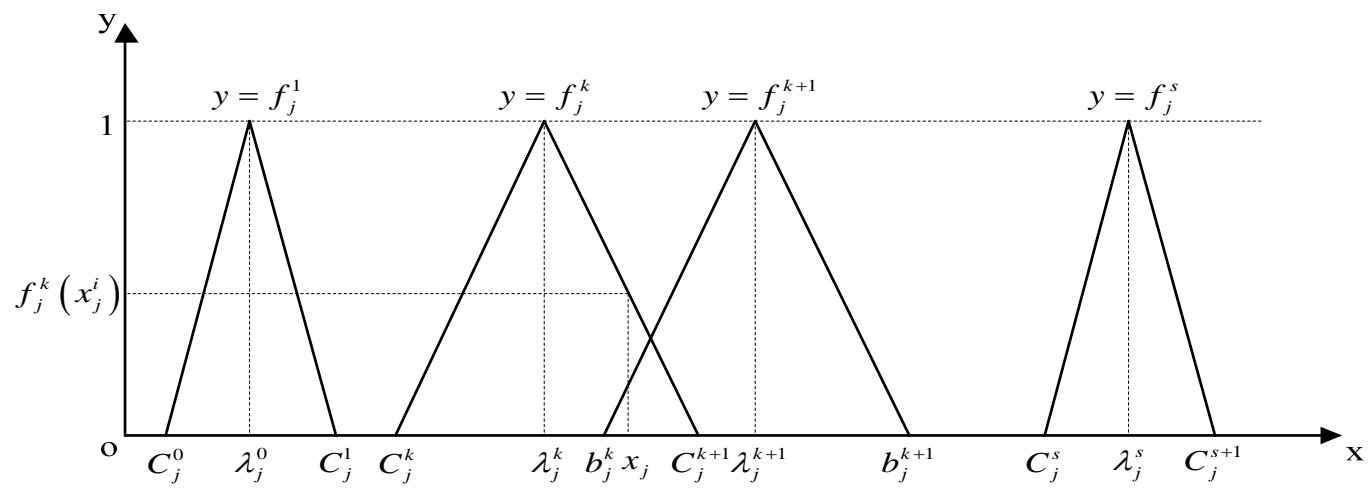

Fig. (2). A sketch of constructing the compact-center-point triangular whitenization weight function.

$\max \left\{f_{j_{0}}^{k-1}\left(x_{j_{0}}^{i}\right), f_{j_{0}}^{k}\left(x_{j_{0}}^{i}\right)\right\}$. It holds that $f_{j}^{k^{\prime}}\left(x_{j}^{i}\right)$ is the triangular whitenization weight function of the evaluation index $g_{j}^{i} \quad$ belonging to the grey cluster $k^{\prime}$. If $\left[c_{j}^{k-1}, c_{j}^{k}\right) \cap\left[b_{j}^{k}, b_{j}^{k+1}\right)=\varnothing$, then we can calculate $f_{j}^{k}\left(x_{j}^{i}\right)$ by Eq. (1). Fig. (2) shows a sketch of constructing the compactcenter-point triangular whitenization weight function.

Step 3: The integrated clustering coefficients for the evaluation criteria $O_{i}$ belonging to the grey cluster $k$ given by:

$\sigma_{i}^{k}=\sum_{j=1}^{m} f_{j}^{k}\left(x_{j}^{i}\right) \eta_{j}^{i}$

where the weight of evaluation index $\eta_{j}^{i}$ is determined by the method of triangular fuzzy number [33].

Then, we have the integrated clustering coefficients matrix for evaluation criteria $O_{i}$ as

$$
\left(\sigma_{i}^{k}\right)_{4 \times 4}=\left[\begin{array}{llll}
\sigma_{1}^{1} & \sigma_{1}^{2} & \sigma_{1}^{3} & \sigma_{1}^{4} \\
\sigma_{2}^{1} & \sigma_{2}^{2} & \sigma_{2}^{3} & \sigma_{2}^{4} \\
\sigma_{3}^{1} & \sigma_{3}^{2} & \sigma_{3}^{3} & \sigma_{3}^{4} \\
\sigma_{4}^{1} & \sigma_{4}^{2} & \sigma_{4}^{3} & \sigma_{4}^{4}
\end{array}\right]
$$

Step 4: We can have the grey clustering result of each criteria based on the principle of the maximum clustering coefficient value. Assuming $\max _{1 \leq k \leq 4}\left\{\sigma_{i}^{k}\right\}=\sigma_{i}^{k^{*}}$, we say that the evaluation criteria $O_{i}$ belongs to the grey cluster $k^{*}$. It means that we can choose the maximal element of a grey clustering coefficient as the clustering result. When more than one objects belong to the grey cluster $k^{*}$, we can sort these objects according to the size of its integrated clustering coefficients, then determine seating arrangement or quality of each object belonging to the grey cluster $k^{*}$.

Based on the above integrated clustering coefficients matrix, we get the following results: (1) In terms of selecting the maximum value of clustering coefficients, the grey clustering result of each criteria can be obtained. (2) Every clustering coefficient should be considered as an evidence to comprehensively evaluate the initial water rights allocation scheme.

\subsection{Combinate the Comprehensive Evaluation Result of Scheme Based on D-S Evidence Theory}

By combinatting the belief function of each evidence with application of Dempster's combination rule, we get the result of allocation scheme evaluation in terms of the principle of selecting the maximum value of belief functions. The main procedure for combinatting the comprehensive evaluation result of the initial water rights allocation scheme based on D-S evidence theory is to first determine the basic probability assignments by analyzing evidence $\delta_{i}^{k}$. Then, the D-S evidence theory is used to obtain the belief function of each evidence with application of Dempster's combination rule. Finally, We can have the comprehensive evaluation result of allocation scheme based on the principle of the maximum belief function value. The procedure for combinatting the comprehensive evaluation result can be generated as:

Step 1: Determine the basic probability assignments.

Let $\Theta=\left\{A_{1}, A_{2}, A_{3}, A_{4}\right\}=\{$ poor type, general type, good type, excellent type $\}$ be the discernment frame of the basin initial water rights allocation scheme, the basic probability assignments belong to the grey clustering coefficient can be calculated by:

$$
m_{i}\left(A_{k}\right)=\frac{\sigma_{i}^{k}}{\sum_{k=1}^{4} \sigma_{i}^{k}}
$$

where $i=1,2,3,4 ; k=1,2,3,4$. For any $k$, there exsits $i_{0}$, such that $\sigma_{i_{0}}^{k} \neq 0$.

Then, the basic probability assignments matrix is expressed by: 


$$
M_{1}=\left[\begin{array}{llll}
m_{1}\left(A_{1}\right) & m_{2}\left(A_{1}\right) & m_{3}\left(A_{1}\right) & m_{4}\left(A_{1}\right) \\
m_{1}\left(A_{2}\right) & m_{2}\left(A_{2}\right) & m_{3}\left(A_{2}\right) & m_{4}\left(A_{2}\right) \\
m_{1}\left(A_{3}\right) & m_{2}\left(A_{3}\right) & m_{3}\left(A_{3}\right) & m_{4}\left(A_{3}\right) \\
m_{1}\left(A_{4}\right) & m_{2}\left(A_{4}\right) & m_{3}\left(A_{4}\right) & m_{4}\left(A_{4}\right)
\end{array}\right]
$$

Step 2: Combinate the belief function by Dempster's rule of combination.

(1) For describe it properly, this paper first describes Dempster's rule of combination. Given some basic probability assignments $m_{1}, m_{2}, \cdots, m_{4}$ defined on the frame of $\Theta$, four focal elements as $A_{1}, A_{2}, A_{3}, A_{4}$, the belief function that results from the application of Dempster's rule combination is given by

$$
m\left(A_{i}\right)=\left(m_{1} \oplus m_{2} \oplus m_{3} \oplus m_{4}\right)\left(A_{i}\right)= \begin{cases}\sum_{A_{1} \cap \cdots \cap A_{4}=A} \prod_{i=1}^{n} m_{i}\left(A_{i}\right) & A \neq \varnothing \\ 0, & A=\varnothing\end{cases}
$$

where $A_{i} \cap A_{j}=\varnothing, i \neq j$ denotes that the two incompatible propositions respectively attained reliabilities by the two evidences exist conflict; $K=\sum_{A_{1} \cap \cdots \cap A_{4}=\varnothing} \prod_{i=1}^{n} m_{i}\left(A_{i}\right)$ denotes the degree of conflict, which measures the conflict among the evidences [32]. The bigger the value $K$, the greater the conflict. Hence, the value of $K$ is used to reflect the degree of conflict among the evidences.

Based on Dempster's rule of combination as Eq.(4), we obtain the belief functions as $m\left(A_{i}\right)=\left(m_{1} \oplus m_{2} \oplus m_{3} \oplus m_{4}\right)$ $\left(A_{i}\right), i=1,2,3,4$.

(2) The case of existing the problem of "0 Absolutization" in evidential reasoning. If there exists the problem of "0 Absolutization" defined by Xu et al. in the process of the evidence combination [34], the weight value will be distorted caused by the over conflict on that problem. Hence, we can improve the basic probability assignment value by adjust set function to solve this problem. The basic idea is to take apart certain set function: the part closed to the original value is still assigned to the original assumption; the other small part is assigned to the assumption that set function is " 0 ".

If there exist $i_{0}, j_{0} \in\{1,2,3,4\}$, such that $m_{j_{0}}\left(A_{i_{0}}\right)=0$. Without loss of generality, we can assume

$m_{j_{0}}\left(A_{i_{0}}\right)=\lambda \min \left\{m_{j}\left(A_{i_{0}}\right) \neq 0, j=1,2,3,4\right\}$

where $\lambda>0$ is determined according to its special combination situation. The value of $m_{j_{0}}\left(A_{i_{0}}\right)$ can be split from the basic probability assignment value $\max \left\{m_{j}\left(A_{i_{0}}\right), j=\right.$ $1,2,3,4\}$. The basic probability assignments values will be improved again until the values exceed the minimum value allowed for the conflict.
Thus, by the Eq.(5) to improve the basic probability assignment value, we have the improved basic probability assignments matrix as $M_{2}$. Again, by Dempster's rule of combination as Eq.(4), we have the belief functions as $m^{*}\left(A_{i}\right)=\left(m_{1}^{*} \oplus m_{2}^{*} \oplus m_{3}^{*} \oplus m_{4}^{*}\right)\left(A_{i}\right), i=1,2,3,4$.

Step 3: Analysis of comprehensive evaluation result. We can have the focal element based on the principle of the maximum belief function value.

(1) Assuming $\max _{1 \leq i \leq 4}\left\{m\left(A_{i}\right), i=1,2,3,4\right\}=m\left(A_{i^{0}}\right)$, we say that the maximum value by Dempster's rule of combination belongs to the focal element $A_{i^{0}}$.

(2) If there exists the problem of " 0 Absolutization" in evidential reasoning. Assuming $\max _{1 \leq i \leq 4}\left\{m^{*}\left(A_{i}\right), i=1,2,3,4\right\}$ $=m^{*}\left(A_{i^{*}}\right)$, we say that the maximum value by Dempster's rule of combination belongs to the focal element $A_{i}$.

Accordding to the correspondence between the grey categorie and the focal element, we have the comprehensive evaluation result of allocation scheme belongs to certain grey categorie on the basis of the above method.

\section{CASE STUDY}

\subsection{General Situation and Research Value of Study Area}

Dalinghe River is the largest single flow in the western of Liaoning province in China. The length of the trunk stream is about $435 \mathrm{~km}$ and the basin area is about 23837 $\mathrm{km}^{2}$. The river stretches across the provinces of Liaoning, Inner Mongolia and Hebei. Its basin area in Liaoning is $20285 \mathrm{~km}^{2}$, which accounts for $85.1 \%$ of the whole. This region belongs to the typical continental monsoon climate characterized by hot and rainy summers, cold and dry winters, which results in uneven amount of precipitation of year and rainfall is concentrated in July and August. Meanwhile the average rainfall of years increases by degrees from north to south. The annual mean precipitation of this basin is between $400 \mathrm{~mm}$ and $600 \mathrm{~mm}$. The per capita possession of water resources of this basin is merely $392 \mathrm{~m}^{3}$, which accounts for $18 \%$ of the national level. In spite of the shortage and conflict of water resources, the frame work, such as the comprehensive scheme of social and economic development of this basin, and the comprehensive scheme of water resources, are relatively complete. Hence, this article selects the initial water rights allocation scheme of Dalinghe River as a case to study.

\subsection{Initial Water Rights Allocation Scheme of Dalinghe River}

According to the society, economy and water resource plan of Dalinghe River, on the basis of the compound system optimization model, we have the initial water rights allocation scheme of Dalinghe River in the programming year (2030) [7, 8]. The scheme is shown in Table 1. 
Table 1. The initial water rights allocation scheme of Dalinghe River in 2030 . (Unit: $10^{4} \mathrm{~m}^{3}$ ).

\begin{tabular}{|c|c|c|c|c|c|c|c|}
\hline Province & City & $\begin{array}{c}\text { Domestic Water } \\
\text { Rights }\end{array}$ & $\begin{array}{c}\text { Agricultural } \\
\text { Water Rights }\end{array}$ & $\begin{array}{c}\text { Industrial } \\
\text { Water Rights }\end{array}$ & $\begin{array}{l}\text { Tertiary Industry } \\
\text { Water Rights }\end{array}$ & $\begin{array}{c}\text { Ecological } \\
\text { Water Rights }\end{array}$ & Total \\
\hline \multirow{3}{*}{$\begin{array}{c}\text { Inner } \\
\text { Mongolia }\end{array}$} & Chifeng & 1091.40 & 2947.31 & 0 & 97.04 & 56.79 & 4192.54 \\
\hline & Tongliao & 180.57 & 2980.68 & 130.98 & 38.94 & 6.45 & 3337.62 \\
\hline & subtotal & 1271.97 & 5927.99 & 130.98 & 135.98 & 63.24 & 7530.16 \\
\hline \multirow{6}{*}{ Liaoning } & Jinzhou & 2285.72 & 17603.83 & 5394.52 & 440.86 & 267.37 & 25992.30 \\
\hline & Fuxin & 5652.91 & 8289.24 & 8960.92 & 1518.73 & 996.61 & 25418.42 \\
\hline & Chaoyang & 10037.92 & 28470.28 & 16623.27 & 1582.84 & 1224.95 & 57939.26 \\
\hline & Panjin & 15.59 & 12219.31 & 38.79 & 0 & 1.02 & 12274.71 \\
\hline & Huludao & 927.84 & 3822.99 & 653.32 & 119.67 & 85.66 & 5609.49 \\
\hline & subtotal & 18919.98 & 70405.65 & 31670.82 & 3662.10 & 2575.61 & 127234.18 \\
\hline Hebei & Chengde & 118.48 & 735.31 & 130.26 & 12.72 & 3.20 & 999.97 \\
\hline \multicolumn{2}{|c|}{ Total } & 20310.43 & 77068.95 & 31932.06 & 3810.80 & 2642.05 & 135764.30 \\
\hline
\end{tabular}

Table 2. The Values and Weights of Evaluation Indexes of Allocation Scheme.

\begin{tabular}{|c|c|c|c|c|}
\hline Object Layer & Criteria Layer & Index Layer & Index Value & Weight \\
\hline \multirow{10}{*}{$\begin{array}{l}\text { The Comprehensive } \\
\text { Evaluation of an } \\
\text { Initial Water Rights } \\
\text { Allocation Scheme }\end{array}$} & \multirow{2}{*}{$\begin{array}{c}\text { Society } \\
x_{1}\end{array}$} & Regional satisfaction of water allocation (\%) $x_{11}$ & 0.889 & 0.127 \\
\hline & & Per-capita water allocation $\left(\mathrm{m}^{3}\right) x_{12}$ & 34.176 & 0.085 \\
\hline & \multirow{3}{*}{$\begin{array}{c}\text { Economic } \\
x_{2}\end{array}$} & Water consumption per ten thousand yuan of agricultural output $\left(\mathrm{m}^{3}\right) x_{21}$ & 0.096 & 0.105 \\
\hline & & Water consumption per ten thousand yuan of industrial output $\left(\mathrm{m}^{3}\right) x_{22}$ & 0.908 & 0.132 \\
\hline & & Water consumption per ten thousand yuan of tertiary industrial output $\left(\mathrm{m}^{3}\right) x_{23}$ & 0.996 & 0.084 \\
\hline & \multirow{2}{*}{$\begin{array}{c}\text { Ecology } \\
x_{3}\end{array}$} & Water with green unit $\left(\mathrm{m}^{3}\right) x_{31}$ & 0.030 & 0.119 \\
\hline & & Satisfaction of water with ecological environment $\left(\mathrm{m}^{3}\right) x_{32}$ & 0.980 & 0.131 \\
\hline & \multirow{3}{*}{$\begin{array}{c}\text { Efficiency } \\
x_{4}\end{array}$} & Utilization coefficient of agricultural water $x_{41}$ & 0.621 & 0.073 \\
\hline & & Utilization coefficient of industrial water $x_{42}$ & 0.930 & 0.092 \\
\hline & & Utilization coefficient of tertiary industrial water $x_{43}$ & 0.869 & 0.052 \\
\hline
\end{tabular}

\subsection{The Comprehensive Evaluation Index System}

\subsubsection{Determine the Integrated Clustering Coefficients Matrix}

(1) Determine the values and weights of evaluation indexes

Based on the connotation and character of the compound system optimization of Dalinghe River initial water rights allocation $[7,8,11]$, as well as the available research results of comprehensive evaluation index system of initial water rights allocation scheme of Dalinghe River, we establish the comprehensive evaluation index system of the basin initial water rights allocation scheme in terms of the investigation and extensive collection of the basin data, and the basin research and interview work, and the suggestion by the river basin administrative agencies and experts in the field of the water environment and water resources, with methods of literature reading, frequency analysis, attribute reduction algorithm, and results reference. According to the related data given by the available research results [7,22], we get the observation values of the evaluation indexes.

Then we figure out the index weights by the method of triangular fuzzy number. Through the triangular fuzzy number to establish judgment matrix based on the importance of evaluation indexes, we obtain the weights of the evaluation indexes by using the third index of Yager to sort the complementary judgment matrix of triangular fuzzy number. As shown in Table 2.

(2) Calculate the integrated clustering coefficient matrix of the indexes of criteria layer

By using the grey clustering evaluation method based on CCTWF, the initial water rights allocation scheme of Dalinghe River is evaluated comprehensively. 
Table 3. The Grey Interval of Grey Cluster Based on the Compact-center-points.

\begin{tabular}{|c|c|c|c|c|}
\hline Index & Poor Type & General Type & Good Type & Excellent Type \\
\hline \hline$x_{11}$ & $0.3 \leq x_{11}<0.7$ & $0.6 \leq x_{11}<0.8$ & $0.75 \leq x_{11}<0.85$ & $0.8 \leq x_{11}<1.0$ \\
\hline$x_{12}$ & $5 \leq x_{12}<15$ & $15 \leq x_{12}<25$ & $25 \leq x_{12}<35$ & $35 \leq x_{12}<45$ \\
\hline$x_{21}$ & $0 \leq x_{21}<0.4$ & $0.3 \leq x_{21}<0.5$ & $0.5 \leq x_{21}<0.7$ & $0.6 \leq x_{21}<1.0$ \\
\hline$x_{22}$ & $0.55 \leq x_{22}<0.75$ & $0.7 \leq x_{22}<0.8$ & $0.8 \leq x_{22}<0.9$ & $0.9 \leq x_{22}<1.0$ \\
\hline$x_{23}$ & $0.75 \leq x_{23}<0.85$ & $0.825 \leq x_{23}<0.875$ & $0.875 \leq x_{23}<0.925$ & $0.90 \leq x_{23}<1.0$ \\
\hline$x_{31}$ & $0.005 \leq x_{31}<0.035$ & $0.028 \leq x_{31}<0.043$ & $0.043 \leq x_{31}<0.058$ & $0.05 \leq x_{31}<0.08$ \\
\hline$x_{32}$ & $0.5 \leq x_{32}<0.7$ & $0.65 \leq x_{32}<0.75$ & $0.75 \leq x_{32}<0.85$ & $0.8 \leq x_{32}<1.0$ \\
\hline$x_{41}$ & $0.3 \leq x_{41}<0.7$ & $0.6 \leq x_{41}<0.8$ & $0.75 \leq x_{41}<0.85$ & $0.8 \leq x_{41}<1.0$ \\
\hline$x_{42}$ & $0.5 \leq x_{42}<0.7$ & $0.65 \leq x_{42}<0.75$ & $0.75 \leq x_{42}<0.85$ & $0.8 \leq x_{42}<1.0$ \\
\hline$x_{43}$ & $0.3 \leq x_{43}<0.7$ & $0.6 \leq x_{43}<0.8$ & $0.75 \leq x_{43}<0.85$ & $0.8 \leq x_{43}<1.0$ \\
\hline
\end{tabular}

Table 4. The Triangular Whitenization Weight Function of the Index Values.

\begin{tabular}{|c|c|c|c|c|c|c|c|c|c|c|}
\hline Code & $x_{11}$ & $x_{12}$ & $x_{21}$ & $x_{22}$ & $x_{23}$ & $x_{31}$ & $x_{32}$ & $x_{41}$ & $x_{42}$ & $x_{43}$ \\
\hline$f_{j}^{1}\left(x_{i j}\right)$ & 0 & 0 & 0.48 & 0 & 0 & 0 & 0 & 0 & 0 & 0 \\
\hline$f_{j}^{1}\left(x_{i j}\right)$ & 0 & 0 & 0 & 0 & 0 & 0.333 & 0 & 0.210 & 0 & 0 \\
\hline$f_{j}^{3}\left(x_{i j}\right)$ & 0 & 0.824 & 0 & 0 & 0 & 0 & 0 & 0 & 0 & 0 \\
\hline$f_{j}^{4}\left(x_{i j}\right)$ & 0.890 & 0 & 0 & 0.160 & 0.080 & 0 & 0.2 & 0 & 0.700 & 0.690 \\
\hline
\end{tabular}

$$
\begin{gathered}
f_{1}^{1}\left(x_{11}\right)=\left\{\begin{array}{ll}
0, & x_{11} \notin[0.3,0.7), \\
\frac{x_{11}-0.3}{0.5-0.3}, & x_{11} \in[0.3,0.5), \\
\frac{0.7-x_{11}}{0.7-0.5}, & x_{11} \in[0.5,0.7),
\end{array} f_{1}^{2}\left(x_{11}\right)= \begin{cases}0, & x_{11} \notin[0.6,0.8), \\
\frac{x_{11}-0.6}{0.7-0.6}, & x_{11} \in[0.6,0.7), \\
\frac{0.8-x_{11}}{0.8-0.7}, & x_{11} \in[0.7,0.8),\end{cases} \right. \\
f_{1}^{3}\left(x_{11}\right)=\left\{\begin{array}{ll}
0, & x_{11} \notin[0.75,0.85), \\
\frac{x_{11}-0.75}{0.8-0.75}, & x_{11} \in[0.75,0.8), \\
\frac{0.85-x_{11}}{0.85-0.8}, & x_{11} \in[0.8,0.85),
\end{array} \quad f_{11}^{4} \notin[0.8,1.0),\right.
\end{gathered}
$$

Step 1: Determine the grey interval of grey cluster. Combining with the suggestion of this river basin administrative agencies and experts in the field of water environment and water resources, and the center-points of the grey cluster, the compact-center-points of the grey cluster are determined. Then, we can obtain the grey interval of grey cluster on the basis of the compact-center-points. As it is shown in Table 3.

Step 2: Calculate the triangular whitenization weight function of the index values. By the Eq.(1), we can calculate the triangular whitenization weight function $f_{j}^{k}\left(x_{i j}\right)$, $k=1,2,3,4$. For the observation value $x_{11}$ of the clustering index $x_{1}, f_{1}^{k}\left(x_{11}\right), k=1,2,3,4$ can be defined as:

For $x_{11}=0.889$, we have $\left(f_{1}^{1}\left(x_{11}\right), f_{1}^{2}\left(x_{11}\right), f_{1}^{3}\left(x_{11}\right)\right.$, $\left.f_{1}^{4}\left(x_{11}\right)\right)=(0,0,0,0.89)$. Then, the others can be calculated similarly to the observation value $x_{11}$. As it is shown in Table 4 .

Step 3: Calculate the integrated clustering coefficients matrix. By the Eq. (2), we have the integrated clustering coefficients matrix of the indexes of criteria layer as 


$$
\left(\delta_{i}^{k}\right)_{4 \times 4}=\left[\begin{array}{llll}
\sigma_{1}^{1} & \sigma_{1}^{2} & \sigma_{1}^{3} & \sigma_{1}^{4} \\
\sigma_{2}^{1} & \sigma_{2}^{2} & \sigma_{2}^{3} & \sigma_{2}^{4} \\
\sigma_{3}^{1} & \sigma_{3}^{2} & \sigma_{3}^{3} & \sigma_{3}^{4} \\
\sigma_{4}^{1} & \sigma_{4}^{2} & \sigma_{4}^{3} & \sigma_{4}^{4}
\end{array}\right]=\left[\begin{array}{cccc}
0 & 0 & 0.070 & 0.110 \\
0.050 & 0 & 0 & 0.027 \\
0 & 0.036 & 0 & 0.026 \\
0 & 0.020 & 0 & 0.100
\end{array}\right]
$$

(3) Analysis of grey clustering result of each criteria

1) According to $\max _{1 \leq k \leq 4}\left\{\sigma_{1}^{k}\right\}=\sigma_{1}^{4}=0.110$, we can see that, for the social rationality in this allocation, the evaluation result of the initial water rights allocation scheme of Dalinghe River belongs to "excellent type" of the grey categories. That is to say, the allocation scheme can reflect the people's wishes of water, and improve people's satisfaction with the initial water rights allocation scheme of Dalinghe River very well. There is no need to redesign the allocation scheme for the social rationality.

2) According to $\max _{1 \leq k \leq 4}\left\{\sigma_{2}^{k}\right\}=\sigma_{2}^{1}=0.050$, we can see that, for the economic rationality in this allocation, the evaluation result of the initial water rights allocation scheme of Dalinghe River belongs to "poor type" of the grey categories. That is to say, the economic rationality in this allocation is at a lower level. In fact, the ten thousand yuan per agricultural water consumption of Panjin is $13728.98 \mathrm{~m}^{3}$, compared with $328.70 \mathrm{~m}^{3}$ of Chengde and $278.53 \mathrm{~m}^{3}$ of Chifeng, and technology of water-saving irrigation of Panjin is extremely poor, which indicates that the water-use efficiency of Panjin is poorer than others. Therefore, on the one hand, the feasibility and effectiveness of the grey clustering evaluation method based on CCTWF can be verified. on the other hand, Panjin should take appropriate measures such as introducing advanced technology to develop water-saving irrigation agriculture and reduce ten thousand yuan output value per agricultural water consumption, for improving the efficiency and benefit of the water-use.

3) According to $\max _{1 \leq k \leq 4}\left\{\sigma_{3}^{k}\right\}=\sigma_{3}^{2}=0.036$, we can see that, for the ecological rationality in this allocation, the evaluation result of the initial water rights allocation scheme of Dalinghe River belongs to "general type" of the grey categories. Actually, the ecological water rights of Panjin according to this allocation scheme is only $1.02 \times 10^{4} \mathrm{~m}^{3}(0.08 \%$ of the total of ecological water rights), while the total of ecological water rights is $2642.05 \times 10^{4} \mathrm{~m}^{3}(1.9 \%$ of the total of ecological water rights). Therefor, the initial water rights allocation scheme of Dalinghe River is not reasonable for the ecological rationality in this allocation to some extent.

4) According to $\max _{1 \leq k \leq 4}\left\{\sigma_{4}^{k}\right\}=\sigma_{4}^{4}=0.100$, we can see that, for the efficiency rationality in this allocation, the evaluation result of the initial water rights allocation scheme of Dalinghe River belongs to "excellent type" of the grey categories. That is to say, the allocation scheme seems excellent for the efficiency rationality in this allocation. There is no need to redesign the allocation scheme for the efficiency rationality.

\subsubsection{Combinate the Comprehensive Evaluation Result with the Results of Each Criteria}

(1) Determine the basic probability assignments

Let $\Theta=\left\{A_{1}, A_{2}, A_{3}, A_{4}\right\}=\{$ poor type, general type, good type, excellent type $\}$. By the Eq.(3), we can calculate the basic probability assignments belong to the grey clustering coefficients $m_{i}\left(A_{k}\right), k=1,2,3,4$. For the basic probability assignment $m_{1}$ defined on the frame of $\Theta$, four focal elements as $\mathrm{A}_{1}, \mathrm{~A}_{2}, \mathrm{~A}_{3}, \mathrm{~A}_{4}, m_{1}\left(A_{k}\right), k=1,2,3,4$ can be defined as:

$$
\begin{gathered}
m_{1}\left(A_{1}\right)=\sigma_{1}^{1} / \sum_{k=1}^{4} \sigma_{1}^{k}=0, m_{1}\left(A_{2}\right)=\sigma_{1}^{2} / \sum_{k=1}^{4} \sigma_{1}^{k}=0, \\
m_{1}\left(A_{3}\right)=\sigma_{1}^{3} / \sum_{k=1}^{4} \sigma_{1}^{k}=0.389, \\
m_{1}\left(A_{4}\right)=\sigma_{1}^{4} / \sum_{k=1}^{4} \sigma_{1}^{k}=0.611,
\end{gathered}
$$

For $m_{1}$, we have $\left(m_{1}\left(A_{1}\right), m_{1}\left(A_{2}\right), m_{1}\left(A_{3}\right), m_{1}\left(A_{4}\right)\right)=$ $(0,0,0.389,0.611)$. Then, the others can be calculated similarly to the basic probability assignment $m_{1}$. As it is shown as follows:

$$
M=\left[\begin{array}{llll}
m_{1}\left(A_{1}\right) & m_{2}\left(A_{1}\right) & m_{3}\left(A_{1}\right) & m_{4}\left(A_{1}\right) \\
m_{1}\left(A_{2}\right) & m_{2}\left(A_{2}\right) & m_{3}\left(A_{2}\right) & m_{4}\left(A_{2}\right) \\
m_{1}\left(A_{3}\right) & m_{2}\left(A_{3}\right) & m_{3}\left(A_{3}\right) & m_{4}\left(A_{3}\right) \\
m_{1}\left(A_{4}\right) & m_{2}\left(A_{4}\right) & m_{3}\left(A_{4}\right) & m_{4}\left(A_{4}\right)
\end{array}\right]=\left[\begin{array}{cccc}
0.000 & 0.649 & 0.000 & 0.000 \\
0.000 & 0.000 & 0.581 & 0.167 \\
0.389 & 0.000 & 0.000 & 0.000 \\
0.611 & 0.351 & 0.419 & 0.833
\end{array}\right]
$$

(2) Combinate the belief function by Dempster's rule of combination

By Dempster's rule of combination as Eq.(4), We can combinate the belief function as

$$
\begin{aligned}
& K_{1}=1-K=\sum_{A_{1} \cap \cdots \cap A_{4} \neq \varnothing} \prod_{i=1}^{4} m_{i}\left(A_{i}\right)=0.075 \\
& \left(m_{1} \oplus m_{2} \oplus m_{3} \oplus m_{4}\right)\left(A_{1}\right)=0,\left(m_{1} \oplus m_{2} \oplus m_{3} \oplus m_{4}\right)\left(A_{2}\right)=0, \\
& \left(m_{1} \oplus m_{2} \oplus m_{3} \oplus m_{4}\right)\left(A_{3}\right)=0,\left(m_{1} \oplus m_{2} \oplus m_{3} \oplus m_{4}\right)\left(A_{4}\right)=1 .
\end{aligned}
$$

Since $m_{1}\left(A_{1}\right)=m_{1}\left(A_{2}\right)=m_{2}\left(A_{2}\right)=m_{2}\left(A_{3}\right)=m_{3}\left(A_{1}\right)=m_{3}\left(A_{3}\right)=m_{4}$ $\left(A_{1}\right)=m_{4}\left(A_{3}\right)=0$, there exists the problem of " 0 Absolutization". For $\left(m_{1}\left(A_{1}\right), m_{1}\left(A_{2}\right), m_{1}\left(A_{3}\right), m_{1}\left(A_{4}\right)\right)=(0,0,0.389$, 0.611 ), we need to improve the values of the basic probability assignments by the Eq.(5) as

where we take $\lambda=0.1$ to improve the value of the basic probability assignments as $m_{1}\left(A_{1}\right), m_{1}\left(A_{2}\right)$, which split from the value of the basic probability assignment as $\min \left\{m_{1}\left(A_{i}\right) \neq 0, i=1,2,3,4\right\}$. The basic probability assign- 


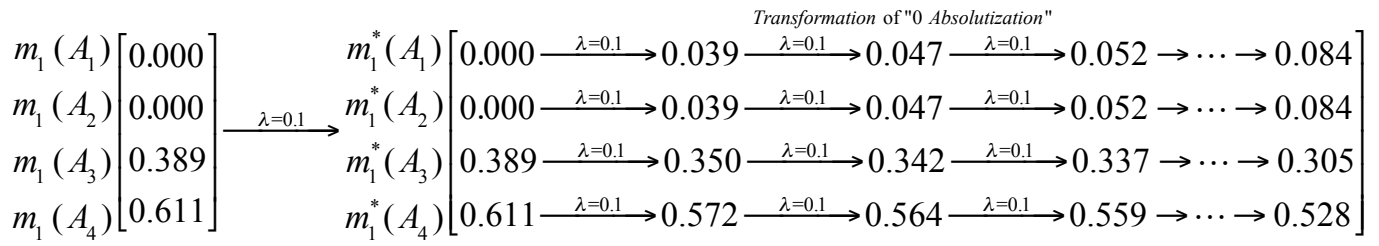

ments values will be improved again until the values exceed the minimum value allowed for the conflict 0.080 . Then, the others can be improved similarly to $\left(m_{1}\left(A_{1}\right), m_{1}\left(A_{2}\right)\right.$, $\left.m_{1}\left(A_{3}\right), m_{1}\left(A_{4}\right)\right)$. As it is shown as follows:

$$
\begin{gathered}
M_{2}=\left[\begin{array}{llll}
m_{1}^{*}\left(A_{1}\right) & m_{2}^{*}\left(A_{1}\right) & m_{3}^{*}\left(A_{1}\right) & m_{4}^{*}\left(A_{1}\right) \\
m_{1}^{*}\left(A_{2}\right) & m_{2}^{*}\left(A_{2}\right) & m_{3}^{*}\left(A_{2}\right) & m_{4}^{*}\left(A_{2}\right) \\
m_{1}^{*}\left(A_{3}\right) & m_{2}^{*}\left(A_{3}\right) & m_{3}^{*}\left(A_{3}\right) & m_{4}^{*}\left(A_{3}\right) \\
m_{1}^{*}\left(A_{4}\right) & m_{2}^{*}\left(A_{4}\right) & m_{3}^{*}\left(A_{4}\right) & m_{4}^{*}\left(A_{4}\right)
\end{array}\right]= \\
{\left[\begin{array}{llll}
0.084 & 0.567 & 0.082 & 0.086 \\
0.084 & 0.083 & 0.499 & 0.081 \\
0.305 & 0.083 & 0.082 & 0.086 \\
0.528 & 0.268 & 0.338 & 0.747
\end{array}\right]}
\end{gathered}
$$

Again, by Dempster's rule of combination as Eq.(4), we have the belief functions as

$$
\begin{aligned}
& K_{2}=\sum_{A_{1} \cap \cdots \cap A_{4} \neq \varnothing} \prod_{i=1}^{4} m_{i}^{*}\left(A_{i}\right)=0.036 \\
& \left(m_{1}^{*} \oplus m_{2}^{*} \oplus m_{3}^{*} \oplus m_{4}^{*}\right)\left(A_{1}\right)=0.009,\left(m_{1}^{*} \oplus m_{2}^{*} \oplus m_{3}^{*} \oplus m_{4}^{*}\right) \\
& \left(m_{1}^{*} \oplus m_{2}^{*} \oplus m_{3}^{*} \oplus m_{4}^{*}\right)\left(A_{3}\right)=0.005,\left(m_{1}^{*} \oplus m_{2}^{*} \oplus m_{3}^{*} \oplus m_{4}^{*}\right)
\end{aligned}
$$$$
\left(A_{2}\right)=0.008 \text {, }
$$$$
\left(A_{4}\right)=0.978 \text {. }
$$

(3) Analysis of comprehensive evaluation result

According to $\max _{1 \leq i \leq 4}\left(m_{1} \oplus m_{2} \oplus m_{3} \oplus m_{4}\right)\left(A_{i}\right)=\left(m_{1} \oplus m_{2}\right.$ $\left.\oplus m_{3} \oplus m_{4}\right)\left(A_{4}\right)=1 \quad$ and $\quad \max _{1 \leq i \leq 4}\left(m_{1}^{*} \oplus m_{2}^{*} \oplus m_{3}^{*} \oplus m_{4}^{*}\right)\left(A_{i}\right)=$ $\left(m_{1}^{*} \oplus m_{2}^{*} \oplus m_{3}^{*} \oplus m_{4}^{*}\right)\left(A_{4}\right)=0.978$, we have that the maximum value of belief functions by Dempster's rule of combination belongs to the focal element $A_{4}$. It shows that the comprehensive evaluation result of allocation scheme of Dalinghe River belongs to "excellent type" on the basis of the above method.

On the one hand, this allocation scheme reflects fairness and efficiency of water allocation among the regions in the compound system, pays attention to ecological and environmental protection and ensures the reasonability and effectiveness of the allocated water among the regions, which is beneficial to coordinated development among all the regions. On the other hand, the procedure of comprehensive evaluation further demonstrates the feasibility and validity of the grey clustering evaluation model based on D-S evidence theory to deal with uncertain problem.

\section{CONCLUSION}

Taking advantages of D-S evidence theory and CCTWF in processing and integrating the uncomplete and uncertain information, proposes the grey clustering evaluation model based on D-S evidence theory. The integrated clustering coefficients matrix is obtained by using the grey clustering evaluation method based on CCTWF, and we take each clustering object as an evidence. Then, the D-S evidence theory is used to obtain the belief function of each evidence with application of Dempster's combination rule, and the result of scheme evaluation is reached from the maximum value of belief functions. Finally, Results of case study of the initial water rights allocation scheme of Dalinghe River in China indicate the feasibility and validity of the proposed method. This new approach, according to fuse the appropriate converted grey clustering coefficients based on Dempster's rule, make full use of the uncertainty information of the clustering objects obtained from the grey clusters and reduce the information loss resulted by merely maximizing the grey coefficients.

\section{CONFLICT OF INTEREST}

The authors confirm that this article content has no conflict of interest.

\section{ACKNOWLEDGEMENTS}

This work was supported by the National Natural Science Foundation (Grant No. 41271537) and the key program of the National Social Science Foundation (Grant No. 12\& ZD214), Ministry of Education (Grant No. 11YJA870007), P.R. China.

\section{REFERENCES}

[1] C. De Fraiture, M. Giordano and Y. Liao, "Biofuels and implications for agricultural water use: blue impacts of green energy", $\mathrm{Wa}$ ter Policy, vol. 10, pp. 67-81, 2008.

[2] Y. P. Li, G. H. Huang and S. L. Nie, "A robust interval-based minimax-regret analysis approach for the identification of optimal water-resources-allocation strategies under uncertainty", Resour. Conserv. Recycl., vol. 54, pp. 86-96, 2009.

[3] H. W. Lu, G. H. Huang and L. He, "Development of an intervalvalued fuzzy linear-programming method based on infinite $\alpha$-cuts for water resources management", Environ. Model. Softw., vol. 25, pp. 354-361, 2010.

[4] S. Wang and G. H. Huang, "Interactive two-stage stochastic fuzzy programming for water resources management ", J. Environ. Manage., vol. 92, pp. 1986-1995, 2011.

[5] F. P. Wu, L. N. Zhang, L. P. Feng and P. Jia, "Grey decisionmaking method based on evidence theory to optimize schemes of water resources allocation", Open Cybern. Syst. J., vol. 7, pp. 3946, 2013.

[6] X. J.Wang, J. Y.Zhang, S. Shamsuddin, E.Amgad, R. M. He, Z. X Bao and A. Mahtab, "Water resources management strategy for adaptation to droughts in China", Mitigation Adaptation Strategies Global Change, vol. 17, pp. 923-937, 2012. 
[7] H. Wang, L. W. Dang and X. M. Xie, "Theory and Practice on Allocation of Initial Water Rights in a Watershed", Beijing: China Water Resources and Hydropower Press, 2008.

[8] D. Wu, F. P. Wu and Y. P. Chen, "Principle-subordinate hierarchical multi-objective programming model of initial water rights allocation", Water Sci. Eng., vol. 2, pp. 105-116, 2009.

[9] X. S. Diao and T. Rao, "Can a water market avert the "doublewhammy" of trade reform and lead to a "win-win" outcome?", $J$. Environ. Econ. Manage., vol. 131, pp. 735-746, 1999.

[10] M. Jennifer, "Water institutional reforms in Australia", Water Policy, vol. 7, pp: 35-52, 2005.

[11] Z. J. Wang, H. Zheng and X. F. Wang, "A harmonious water rights allocation model for Shiyang River basin, Gansu Province, China", Water Resour. Dev., vol. 25, pp. 355-371, 2009.

[12] C. C. Ruml, "Coase theorem and western US appropriative water rights", Nat. Resour. J., vol. 45, pp.169, 2005.

[13] F. P. Wu, P. Jia and L. N. Zhang, "Comprehensive evaluation of water resource allocation schemes based on lattice-order theory". Resour. Sci., vol. 35, pp. 2232-2238, 2013.

[14] L. N. Zhang, F. P. Wu and P. Jia, "Grey evaluation model based on reformative triangular whitenization weight function and its application in water rights allocation system", Open Cybern. Syst. J., vol. 7, pp 1-10, 2013

[15] J. Xu, Y. Tu and Z. Zeng, "Bilevel optimization of regional water resources allocation problem under fuzzy random environment", $J$. Water Resour. Planning Manage., vol. 139, pp. 246-264, 2012.

[16] J. X. Yu, X. G. Jiang and J. J. Lian, "Comprehensive evaluation model for optimal deployment of water resources based on fuzzy theory and information entropy", J. Hydraulic Eng., vol. 40, pp. 729-735, 2009.

[17] W. R. Wang and M. Z. Tu, "Calculating of proportion based on analytic hierarchy process in basin water allocation", J. Tongji Univ. (Nat. Sci.), vol. 33, pp. 1133-1136, 2005.

[18] A. Lilienfeld and M. Asmild, "Estimation of excess water use in irrigated agriculture: a data envelopment analysis approach", Agric. Water Manage., vol. 94, pp. 73-82, 2007.

[19] S. F. Liu and Y. D. Zhu, "Study on triangular model and indexes in synthetic evaluation of regional economy", Chin. Soc. Agric. Eng., vol. 9, pp. 8-13, 1993.
[20] S. F. Liu, "On index system and mathematical model for evaluation of scientific and technical strength", Kybenetes, vol. 35, pp. 12561264, 2006.

[21] S. F. Liu, Y. G. Dang and Z. G. Fang, "Grey System Theory and Its Applications", Beijing, China: Science Press, 2010.

[22] W. Meng, S. F. Liu, B. Zeng and N. M. Xie, "Standard triangular whitenization weight function and its application in grey clustering evaluation", J. Grey Syst., vol. 24, pp. 39-48, 2012.

[23] S. F. Liu and N. M. Xie, "New grey evaluation method based on reformative triangular whitenization weight function", J. Syst. Eng., vol. 38, pp. 8938-8948, 2011.

[24] C. B. Madhuri and J. A. Chandulal, "Evaluating web sites using COPRAS-GRA combined with grey clustering", Int. J. Eng. Sci., vol. 2, pp. 5280-5294, 2010.

[25] J. F. Zhang, Z. J. Wu, P. F. Feng and D. W. Yu, "Evaluation systems and methods of enterprise information and application", Expert Syst. Appl., vol. 38, pp. 8938-8948, 2011.

[26] Y. Guo, Q. L. Zhou and J. B. Huang, "The grey evaluation of road traffic safety based on triangular whitening weight function", Chin. Sci., vol. 8, pp. 87-90, 2006.

[27] J. J. Liu, W. Wang and L. Cheng, "The grey number evaluation of road net based on trigonometry whitening weight function", Syst. Eng. Theory Pract., vol. 27, pp. 156-160, 2007.

[28] Y. M. Wang, J. B. Yang and D. L. Xu, "Environmental impact assessment using the evidential reasoning approach", Eur. J. Oper. Res., vol. 174, pp. 1885-1913, 2006.

[29] Y. H. Wang, Y. G. Dang, "Method of grey fixed weight clustering comprehensive ex-post evaluation based on D-S evidential theory", Syst. Eng.: Theory Pract., vol. 29, pp. 123-128, 2009.

[30] A. P. Dempster, "Upper and lower probabilities induced by a multivalued mapping", Ann. Math. Stat., vol. 38, pp. 325-339, 1967.

[31] A. P. Dempster, "A generalization of Bayesian inference", $J . R$. Stat.. Soc., vol. B30, pp. 205-247, 1968.

[32] G. Shafer, "A Mathematical Theory of Evidence," in NJ: Princeton University Press, 1976.

[33] R. Fullér, "On hamacher sum of triangular fuzzy numbers", Fuzzy Set. Syst., vol. 42, pp. 205-212, 1991.

[34] C. F. Xu, W. D. Geng and Y. H. Pan, "Method to Solve a kind of "0 Absolutization" Problems in evidence reasoning", Comput. Sci., vol. 27, pp. 53-56, 2007.

Received: August 18, 2014

Revised: October 27,2014

Accepted: November 20, 2014

(C) Zhang et al.; Licensee Bentham Open.

This is an open access article licensed under the terms of the Creative Commons Attribution Non-Commercial License (http://creativecommons.org/licenses/by-nc/3.0/) which permits unrestricted, non-commercial use, distribution and reproduction in any medium, provided the work is properly cited. 